\title{
SBA-15 silicas containing sucrose
}

\section{Chemical, structural, and thermal studies}

\author{
M. Barczak • M. Oszust-Cieniuch • P. Borowski • \\ Z. Fekner · E. Zięba
}

ICVMTT2011 Conference Special Chapter

(C) The Author(s) 2011. This article is published with open access at Springerlink.com

\begin{abstract}
Mesoporous silicas were synthesized by condensation of tetraethoxysilane (TEOS) in the presence of Pluronic P123 as a structure-forming agent, and sucrose as an auxiliary agent, to investigate the effect of sucrose and aging temperature on the final properties, particularly structure-adsorption characteristics. Obtained materials have been characterized by XRD, nitrogen sorption measurements SEM-EDX, TEM, thermogravimetry, and FT-IR. The obtained materials have well-developed porous structure-values of the specific surface area $\left(S_{\mathrm{BET}}\right)$ are in the range of $300-950 \mathrm{~m}^{2} / \mathrm{g}$ and the sizes of primary mesopores are in the range of $9-11 \mathrm{~nm}$. It was established that $S_{\mathrm{BET}}$ and ordering significantly decreases with an increasing content of sucrose in the initial mixture.
\end{abstract}

Keywords Mesoporous silica - SBA-15 - Sucrose · Pluronic P123 · Porosity · Adsorption

\section{Introduction}

During the last 20 years, a significant progress has been achieved in the field of ordered mesoporous silicas (OMSs) [1-3]. OMSs constitute an exciting field in materials chemistry due to many potential applications in catalysis, sensing, separation, and adsorption processes [4-6].

M. Barczak $(\bowtie) \cdot$ M. Oszust-Cieniuch · P. Borowski ·

Z. Fekner

Faculty of Chemistry, Maria Curie-Sklodowska University,

Maria Curie-Sklodowska Sq. 3, 20-031 Lublin, Poland

e-mail:mbarczak@umcs.eu

E. Zięba

Department of Zoology and Ecology, SEM Laboratory, Catholic University of Lublin, Krasnicka St. 102, 20-718 Lublin, Poland
In particular, the SBA-15 materials have become one of the most popular ordered silica nanomaterials for several reasons: large mesopores (even up to $15 \mathrm{~nm}$ ), thicker pore walls, and the presence of the network of irregular interconnecting micropores [7-10]. Moreover, these materials have higher thermal and hydrothermal stabilities than MCM-41 materials, due to thicker mesopores walls. SBA15 materials are usually synthesized under strong acidic conditions in the presence of amphiphilic triblock copolymer-Pluronic P123. The synthesis is carried out via controlled hydrolysis and condensation of tetraethoxysilane (TEOS), followed by removal of the polymeric template by either extraction with ethanol and acid or calcination at elevated temperatures.

One of the scientific applications of SBA-15 silicas is their use as hard templates for the synthesis of ordered mesoporous carbons (i.e., CMK-3, CMK-5). Sucrose is one of the most frequently used carbon precursors in such syntheses as it gives the best structurally ordered materials and the most reproducible results [11-13]. Sucrose is also sometimes used as auxiliary agent which helps to stabilize the ordered mesostructure (particularly, when 3-aminopropyltriethoxysilane (APTS) is added during the synthesis). Amino-functionalized mesostructures are very difficult to assemble under acidic conditions, so the final mesoporous silica synthesized by direct co-condensation of TEOS and APTS is disordered when monomers are mixed simultaneously [14-16]. Under strong acidic condition, protonated aminopropyl groups strongly interfere the self-assembling of the surfactant with the silica precursor [17]. Despite the fact that the exact role of sucrose in the self-assembly of the surfactant molecules is still not clear, it is thought that strong interaction between the protonated amino functional groups with the cationic surfactant under acidic conditions can be regulated by this additive [18]. On the other hand, the 
presence of sucrose can strongly affect the structureadsorption characteristics of the final materials; thus, it is very interesting to investigate the influence the sucrose addition on the final properties, particularly, porous structure of the SBA-15 mesoporous materials.

In this study, SBA-15 silicas were synthesized via condensation of TEOS in the presence of Pluronic P123 as structure-forming agent and sucrose as auxiliary agent. Obtained materials were fully characterized to elucidate the influence of the synthesis parameters (such as amount of sucrose added or temperature of aging) on the structureadsorption characteristics.

\section{Experimental}

\section{Materials}

Synthesis of SBA-15 materials was carried out using the following reagents: tetraethoxysilane (TEOS, 96\%, ABCR), Pluronic P123 (P123, BASF), sucrose (Polish Sugar, National Sugar Company), hydrochloric acid (36\%, $\mathrm{POCH})$, ethanol $(99.8 \%, \mathrm{POCH})$, and deionized water (DW; resistivity $<17.5 \mathrm{M} \Omega \mathrm{cm}$ ). All chemicals were used as received, without further purification.

\section{Synthesis}

Syntheses of all channel-like mesoporous silicas were performed by co-condensation of TEOS and proper organotrialkoxysilane in the presence of Pluronic P123. All materials were synthesized by one-pot route using similar synthesis procedure. In a model synthesis, $2 \mathrm{~g}$ of P123 was dissolved in $60 \mathrm{ml}$ of $2 \mathrm{M} \mathrm{HCl}$ and $11 \mathrm{ml}$ of deionized water under vigorous stirring at $40{ }^{\circ} \mathrm{C}$. After $4 \mathrm{~h}$ of stirring, a given amount of sucrose was added (NO-0 g, N2-2 g, N5$5 \mathrm{~g}, N 10-10 \mathrm{~g}$, and N20-20 g). After next $4 \mathrm{~h}$ of stirring, TEOS was added dropwise to this solution. The resulting mixture was stirred at $40{ }^{\circ} \mathrm{C}$ for $24 \mathrm{~h}$ and aged at 70,85 , or $100{ }^{\circ} \mathrm{C}$ for next $48 \mathrm{~h}$. The obtained white solid was thoroughly washed with deionized water, filtered, and dried at $70{ }^{\circ} \mathrm{C}$. The template was removed by 3 -fold extraction with acidic absolute ethanol $(99.8 \%)$ at $70{ }^{\circ} \mathrm{C}$.

\section{Characterization}

XRD patterns were recorded using a Seifert RTG DRON-3 diffractometer $\left(\mathrm{CuK} \alpha\right.$ radiation) with $0.02^{\circ}$ step and $10 \mathrm{~s}$ time step over a range of $0.5^{\circ}<2 \theta<5.0^{\circ}$ at RT. Nitrogen sorption isotherms were measured at $-196^{\circ} \mathrm{C}$ by ASAP $2405 \mathrm{~N}$ adsorption analyzer (Micromeritics). Before adsorption measurements, each sample was degassed (at $110{ }^{\circ} \mathrm{C}$ ). Infrared spectra were recorded at RT by means of
1725X Perkin-Elmer FT-IR spectrometer over the $4000-400 \mathrm{~cm}^{-1}$ range at the resolution of $4 \mathrm{~cm}^{-1}$. TG analysis was carried out under air atmosphere using Setsys 16/18 Setaram analyzer. TG patterns were recorded over a temperature range from 30 to $900{ }^{\circ} \mathrm{C}$. The instrument was equipped with a ceramic $\mathrm{Al}_{2} \mathrm{O}_{3}$ pan. The heating rate was $5{ }^{\circ} \mathrm{C} / \mathrm{min}$, and the air flow rate was $1 \mathrm{dm}^{3} / \mathrm{h}$.

\section{Results}

X-ray diffractometry (XRD)

Figure 1 presents the XRD patterns of the selected samples. Under investigated conditions, mesostructured materials, albeit with different degree of order, were obtained. Three usually well-resolved peaks in the case of samples N0-X, N2-X (X stands for aging temperature) are observed in the range of $2 \theta \approx 0.8^{\circ}-2^{\circ}$ (c.f. Fig. $1-N 0-100$ sample). In the case of these samples, three peaks can be indexed according to hexagonal p6mm symmetry, indicating a well-defined SBA-15 mesostructure: one sharp reflection at $2 \theta \approx 0.8$ indexed as $(100)$ and two minor but distinct reflections at $2 \theta \approx 1.3$ and $2 \theta \approx 1.6$ indexed as (110) and (200), respectively. All three signals disappear gradually with an increasing content of sucrose (c.f. Fig. $1-N 5-100$ and $\mathbf{N 2 0 - 1 0 0}$ samples), what clearly shows that the order of the samples deteriorates.

\section{Nitrogen sorption measurements}

Nitrogen isotherms for the majority of samples have a sharp hysteresis loop (see Fig. 2, left), reflecting capillary

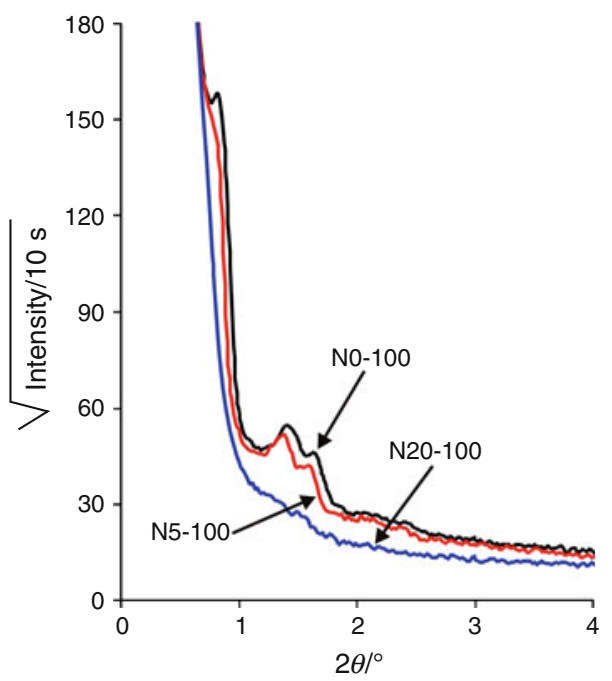

Fig. 1 XRD patterns of the samples N0-100, N5-100, and N20-100 
Fig. 2 Nitrogen sorption isotherms of the samples N2-100 (left) and N20-100 (right) and corresponding pore size distributions (as inlets)

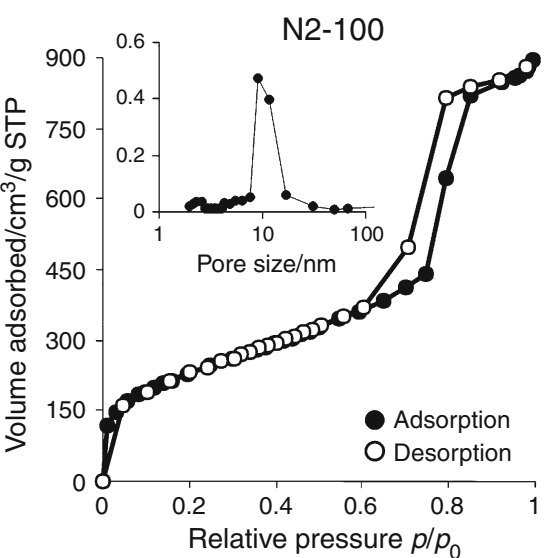

condensation of adsorbate in the uniform mesopores channels, and evaporation step related to the evacuation of adsorbate from the pores. Thus, a framework of these materials has a uniform array of mesopores with the same diameter, what is consistent with XRD and TEM data.

The properties of the porous structures are summarized in Table 1. The pure silica sample N0-70 and sucrosemodified N2-70 samples have the highest specific surface area, $S_{\mathrm{BET}}$, value-947 and $969 \mathrm{~m}^{2} / \mathrm{g}$, respectively. In general, values of $S_{\mathrm{BET}}$ decrease significantly with an increasing content of sucrose. In the series of materials within the same amount of sucrose added, $S_{\mathrm{BET}}$ values decreases with an increase of the aging temperature (the only exception is $\mathbf{N 2 0 - X}$ series, where $\mathbf{N 2 0 - 8 5}$ sample has the highest $S_{\mathrm{BET}}$ value). So, the initial amount of sucrose and the aging temperature, both have a significant effect on the final surface area.

Pore volumes $\left(V_{\mathrm{BJH}}, V_{\mathrm{KJS}}\right)$ also differ among the investigated samples. The $\mathbf{N 0}-\boldsymbol{X}, \boldsymbol{N} \mathbf{2}-\boldsymbol{X}$, and $\boldsymbol{N 5}-\boldsymbol{X}$ samples have pore volumes higher than $1 \mathrm{~cm}^{3} / \mathrm{g}$. The pore volumes for the $\mathbf{N 2 0}-\boldsymbol{X}$ series are significantly smaller than for the rest of the samples. However, no straightforward trends in the changes of $\mathrm{V}_{\mathrm{P}}$ are observed, as in the case of the $S_{\mathrm{BET}}$ values. In general, pore volumes decrease with a decrease of the aging temperature. As it can be seen from the KJS analysis, more than $80 \%$ of the total pore volume is connected with the presence of mesopores bigger than $5 \mathrm{~nm}$, and less than $20 \%$ is due to the presence of interconnecting pores (micropores and mesopores smaller than $5 \mathrm{~nm}$ ). As can be seen from the Table 1, the volume of the mesopores

Table 1 Structural and adsorption characteristics of the samples studied

\begin{tabular}{|c|c|c|c|c|c|c|c|}
\hline Sample name & $\begin{array}{l}S_{\mathrm{BET}} / \\
\mathrm{m}^{2} / \mathrm{g}^{\mathrm{a}}\end{array}$ & $d_{\mathrm{BJH}} / \mathrm{nm}^{\mathrm{b}}$ & $d_{1 \_\mathrm{KJS}}($ micro $) / \mathrm{nm}^{\mathrm{c}}$ & $d_{2 \_\mathrm{KJS}}(\mathrm{meso}) / \mathrm{nm}^{\mathrm{d}}$ & $\begin{array}{l}V_{\mathrm{P}}(\text { total }) / \\
\mathrm{cm}^{3} / \mathrm{g}^{\mathrm{e}}\end{array}$ & $\begin{array}{l}V_{1 \_ \text {KJS }}(\text { micro }) / \\
\mathrm{cm}^{3} / \mathrm{g}^{\mathrm{f}}\end{array}$ & $\begin{array}{l}V_{2 \_ \text {KJS }}(\text { meso }) / \\
\mathrm{cm}^{3} / \mathrm{g}^{\mathrm{g}}\end{array}$ \\
\hline N0-70 & 947 & 5.0 & - & - & 1.18 & - & - \\
\hline N0-85 & 890 & 5.6 & - & - & 1.24 & - & - \\
\hline N0-100 & 778 & 7.0 & 2.3 & 10.7 & 1.36 & 0.14 & 1.28 \\
\hline $\mathrm{N} 2-70$ & 969 & 5.0 & - & - & 1.20 & - & - \\
\hline $\mathrm{N} 2-85$ & 847 & 5.6 & - & - & 1.18 & - & - \\
\hline $\mathrm{N} 2-100$ & 823 & 6.6 & 2.6 & 9.2 & 1.37 & 0.15 & 1.25 \\
\hline N5-70 & 904 & 5.0 & - & - & 1.13 & - & - \\
\hline N5-85 & 759 & 5.5 & - & - & 1.04 & - & - \\
\hline N5-100 & 653 & 6.7 & 2.4 & 9.2 & 1.09 & 0.13 & 0.97 \\
\hline N10-70 & 770 & 4.8 & - & - & 0.92 & - & - \\
\hline N10-85 & 572 & 5.2 & - & - & 0.75 & - & - \\
\hline N10-100 & 448 & 6.6 & 2.5 & 9.3 & 0.74 & 0.08 & 0.67 \\
\hline $\mathrm{N} 20-70$ & 318 & 4.4 & - & - & 0.35 & - & - \\
\hline $\mathrm{N} 20-85$ & 485 & 4.0 & - & - & 0.48 & - & - \\
\hline $\mathrm{N} 20-100$ & 336 & 5.4 & 2.6 & 10.7 & 0.46 & 0.10 & 0.36 \\
\hline
\end{tabular}

${ }^{\mathrm{a}}$ BET specific surface area evaluated in the $0.05-0.25$ range of relative pressures [21], ${ }^{\mathrm{b}}$ Average pore size by BJH method [19], ${ }^{\mathrm{c}}$ Average size of the pores smaller than $5 \mathrm{~nm}$ by KJS method [20], ${ }^{\mathrm{d}}$ Average size of the pores bigger than $5 \mathrm{~nm}$ by KJS method [20], ${ }^{\mathrm{e}}$ Total pore volume calculated by converting the amount adsorbed at a relative pressure about 0.99 to the volume of liquid adsorbate, ${ }^{\mathrm{f}}$ Volume of the pores smaller than $5 \mathrm{~nm}$ by KJS method [20], ${ }^{\mathrm{g}}$ Volume of the pores bigger than $5 \mathrm{~nm}$ by KJS method [20] 
$\left(V_{2}\right.$ KJS $)$ decreases significantly with an increasing amount of sucrose; the volume of pores less than $5 \mathrm{~nm}\left(\mathrm{~V}_{1 \_\mathrm{KJS}}\right)$ also decreases (apart from the $\mathbf{N 2 - 1 0 0}$ sample). The $V_{1} / V_{2}$ ratio for the all series (apart N20-X one) is around 0.11-0.14. In the case of the $\mathbf{N 2 0 - X}$ series, this ratio is equal 0.28 so there is relatively much less mesopores in the structure (this is also supported by "flattened" shape of the isotherm-c.f. Fig. 2, and small $S_{\mathrm{BET}}$ values).

Pore sizes were calculated using BJH [19] (for all the samples) and KJS [20] (for the series $N X-100$ ) method ( $d_{\mathrm{BJH}}$ and $d_{\mathrm{KJS}}$, respectively), which are commonly used to calculate pore size distributions of SBA-15 materials. However, the $\mathrm{BJH}$ method tends to underestimate the average pore size, so usually the KJS method is recommended for more accurate calculations. Average pore sizes of ordered mesopores $\left(d_{2}\right.$ KJS $)$ of all ordered samples calculated by KJS method are in the range of $9.2-10.7 \mathrm{~nm}$. N0-100 and N20-100 samples have mesopore diameters significantly wider than the remaining samples. There are no significant changes of the average diameters in the case of interconnecting pores smaller than $5 \mathrm{~nm}\left(d_{1 \_\mathrm{KJS}}\right)$-for analyzed $N X-100$ samples values of $\left(d_{1 \_ \text {KJS }}\right)$ are in the narrow range of $2.3-2.6 \mathrm{~nm}$. Pore size distributions have bimodal character (c.f. Fig. 2) reflecting the presence of the micropores and mesopores in the structure of obtained materials.
Fig. 3 SEM images of the sample N0-100 (left panel) and N20-100 (right panel)
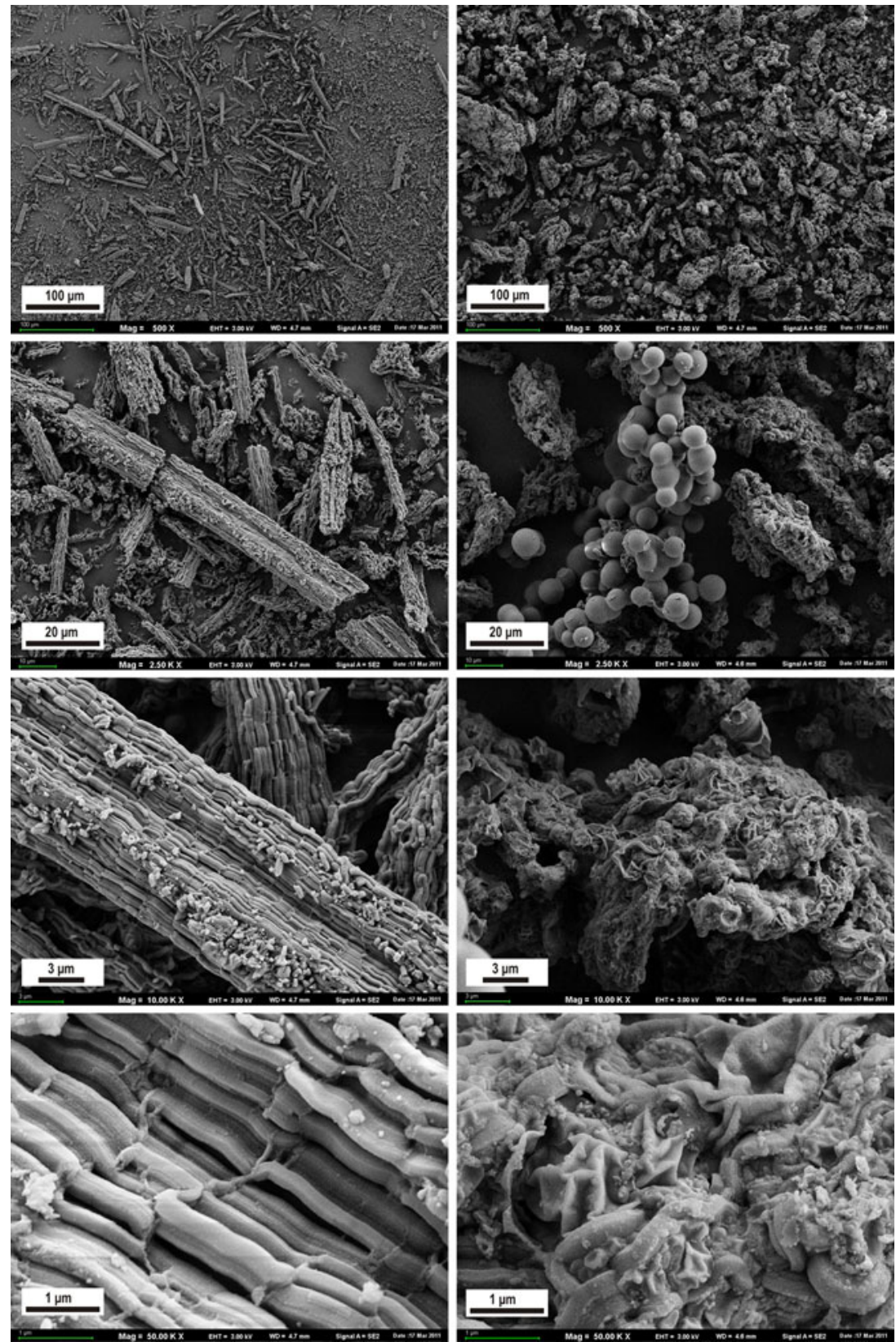


\section{SEM-EDX and TEM microscopy}

SEM micrographs of N0-100 and N20-100 samples are presented in Fig. 3. The difference in morphology of the samples is easily noticed. In the case of pure silica N0-100 material (as well as for N2-100 and N5-100), the material is composed of irregular "needle-like" particles having worm-like structure, i.e., they are composed of parallelly oriented hexagonal motifs. In the case of N20-100 sample, the particles are also quite irregular but they are not needlelike and they have folded(???) structure. The separation into two phases is observed in the case of the samples N10100 and N20-100. Detailed analysis by EDX spectroscopy reveals-apart from morphological differences-different elemental compositions of the phases, what is presented in Fig. 4. In the region 1, organic sucrose-originated phase is observed, while in the region 2 there is mixed silica/ organic phase.

TEM pictures complement the results obtained by XRD method. Figure 5 exemplifies the typical hexagonal structure with homogeneous and ordered pores.

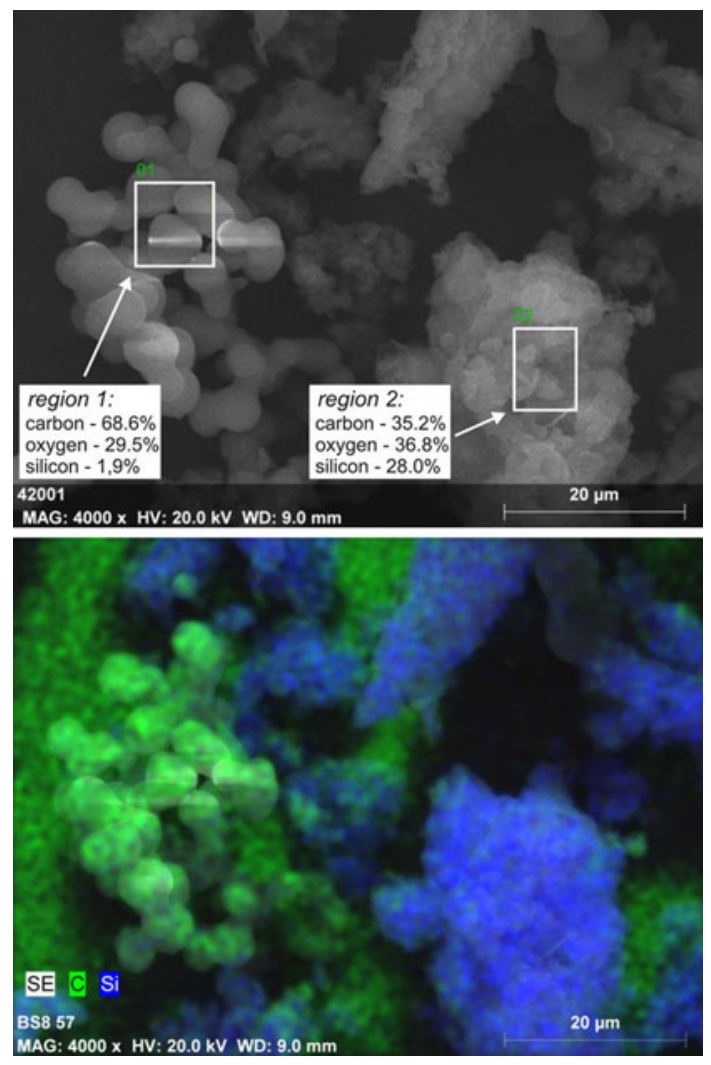

Fig. 4 SEM-EDX analysis of the sample N20-100: elemental composition of two different phases (up), carbon and silicon mapping (bottom)

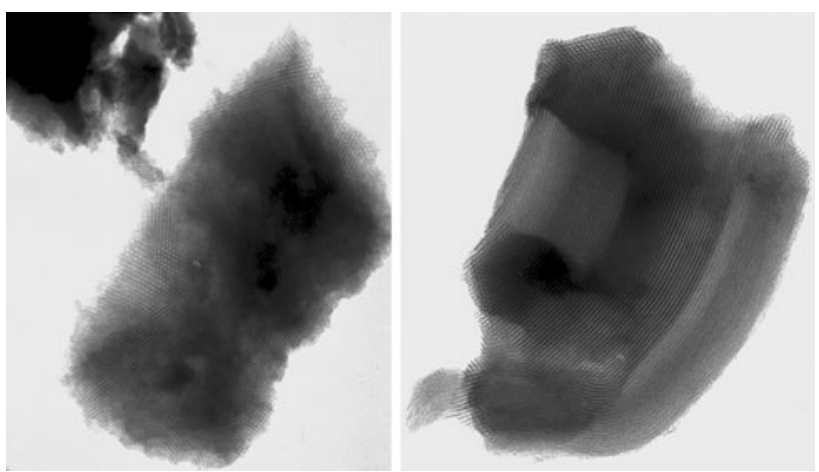

Fig. 5 TEM images of the sample N0-100 (left) and N5-100 (right)

Thermogravimetry and elemental analysis

TG patterns of the samples $N \boldsymbol{N}-\mathbf{1 0 0}$ and the corresponding differential TG (DTG) patterns are given in Fig. 6 showing unresolved overlapping peaks. There are differences in the temperature at which a maximum rate of weight loss is observed (i.e., peak temperature) for each decomposition stage as well as in the intensities of these peaks among the samples. In the range of the temperatures from 35 to $150{ }^{\circ} \mathrm{C}$, thermodesorption of physisorbed water and traces of ethanol takes place. The presence of two DTG peaks in the region of $60-120{ }^{\circ} \mathrm{C}$ suggests that the above-mentioned desorption process occurs in two different types of pores, what indirectly confirms bimodal porous structure of the samples, i.e., the presence of primary mesopores and interconnecting micropores + smaller mesopores. First,
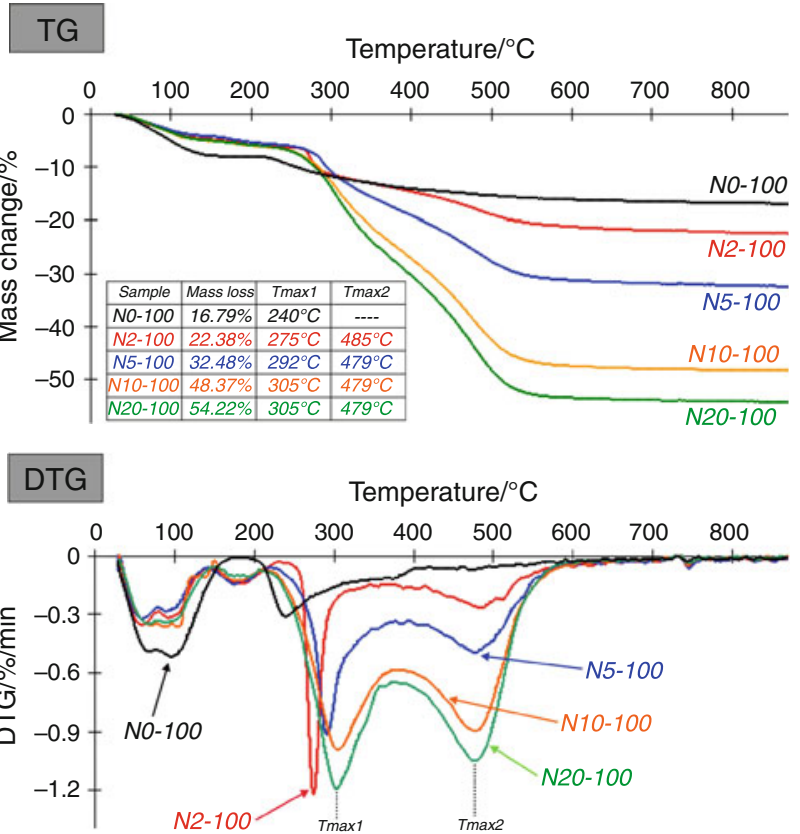

Fig. 6 TG profiles of the samples N0-100-N20-100 (up) and the corresponding DTG profiles (down) 
thermodesorption of water takes place first from the mesopores, then from the micropores [22].

In the range from 150 to $600{ }^{\circ} \mathrm{C}$, decomposition of incorporated template (Pluronic P123) and partially carbonized sucrose takes place $[23,24]$. In the case of pure silica N0-100, the mass change corresponding to the removal of organics is around 9\% indicating that it is hardly possible to remove P123 completely by the extraction procedure [25].

These two processes (i.e., decomposition of P123 and sucrose) occur stepwise- two quite well separated peaks can be seen on corresponding DTG profile at $\sim 300$ and $\sim 480{ }^{\circ} \mathrm{C}$. Moreover, assuming that the same amount of unextracted P123 $(\sim 8-9 \%)$ is present in all samples (which is reasonable in a view of the same synthesis procedure), the DTG peak at $\sim 480{ }^{\circ} \mathrm{C}$ (not present in the case of pure silica N0-100 sample) should reflect only the decomposition of sucrose residues. This implies that the DTG peak located $\sim 300{ }^{\circ} \mathrm{C}$ should be connected with both decomposition of Pluronic and loosely spaced sucrose (c.f. Fig. 4a-Region 1). This peak widens and shifts towards higher temperatures with an increasing content of sucrose. This may suggest that the traces of P123 and sucrose form some kind of mesophase which is different (as far as thermal properties are considered) from the pure P123 mesophase.

Small mass changes $(<1 \%)$ above $600{ }^{\circ} \mathrm{C}$ reflect the condensation of silanol groups and decomposition of some residual organic groups.

\section{Infrared spectroscopy}

FT-IR spectra of samples N0-100, N5-100, and N20-100 are shown in Fig. 7. The common feature of all spectra is

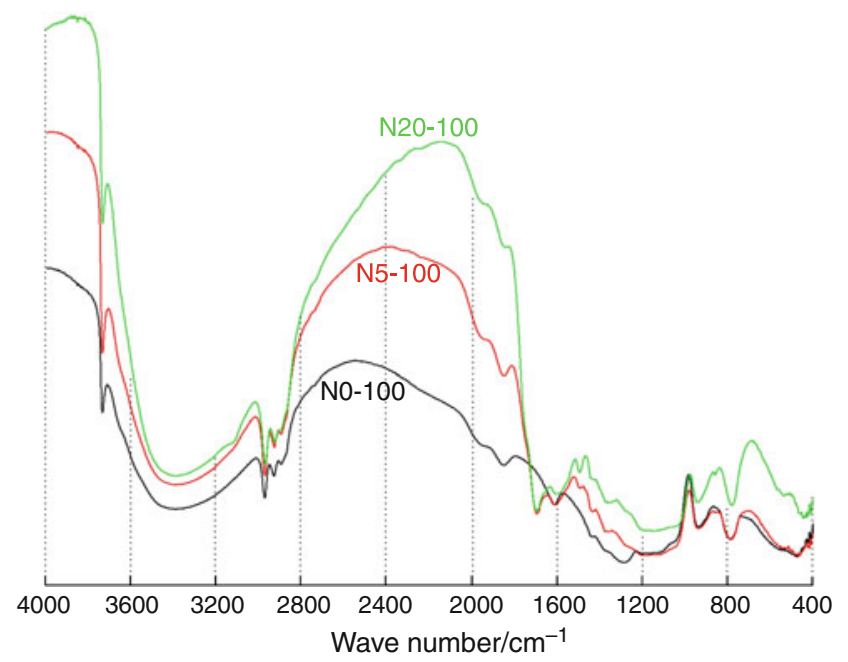

Fig. 7 FT-IR/PAS spectra of the samples N0-100, N5-100, and N20-100 the presence of bands characteristic to silica. Sharp, medium intensity band at $\sim 3740 \mathrm{~cm}^{-1}$ corresponds to the stretching vibrations of the $\mathrm{OH}$ groups in silanol $\mathrm{SiOH}$ fragments. Broad and intense band above $1050 \mathrm{~cm}^{-1}$ is unambiguously attributed to the stretching vibration of the siloxane framework $\equiv \mathrm{Si}-\mathrm{O}-\mathrm{Si} \equiv$. Our recent observations based on the calculated vibrational spectra suggest that these vibrations are frequently accompanied by the inplane bending of the hydrogen bonded $\mathrm{SiOH}$ fragments. Inplane bending of $\equiv \mathrm{Si}-\mathrm{O}-\mathrm{Si} \equiv$ and out-of-plane vibrations of $\mathrm{OSiOH}$ fragments are responsible for the presence of bands around 450 and $800 \mathrm{~cm}^{-1}$, respectively. The broad and intense band with maximum at about $3400 \mathrm{~cm}^{-1}$ corresponds to the stretching vibration of the physically adsorbed water, which is also responsible for the presence of a much weaker band above $1620 \mathrm{~cm}^{-1}$ (the symmetric bending vibration). The aliphatic chains (methylene-based links and possibly residual methyl groups of unhydrolyzed ethoxy groups) are easily identified in the high-frequency range, above $2900 \mathrm{~cm}^{-1}$ - the presence of sharp bands that emerge on the red wing of the water stretching vibration is a clear evidence for the presence of aliphatic methylene and/or methyl groups.

The main difference between spectrum of pure silica (NO sample) and the remaining spectra is the presence of a band close to $1710 \mathrm{~cm}^{-1}$. The only reasonable explanation is that it corresponds to the stretching vibration of the carbonyl groups. Note that the synthesis takes place under strong acidic conditions, which enable hydrolysis of sucrose. Carbonyl groups (which are responsible for strong band of variable location, typically around $1700 \mathrm{~cm}^{-1}$ depending on their surrounding) may appear as a consequence of thermal decomposition of sucrose and products of its hydrolysis at elevated temperatures of the aging process.

\section{Conclusions}

Mesoporous silicas were synthesized by condensation of TEOS in the presence of sucrose. Obtained materials have been characterized by XRD, nitrogen sorption measurements SEM-EDX, TEM, thermogravimetry, and FT-IR spectroscopy. Majority of the samples have well-developed porous structure-values of specific surface area $\left(S_{\mathrm{BET}}\right)$ are in the range of $300-950 \mathrm{~m}^{2} / \mathrm{g}$ and the sizes of primary mesopores are in the range of $9-11 \mathrm{~nm}$. It was established that $S_{\mathrm{BET}}$ and structure order significantly decreases with increasing content of sucrose in the initial mixture. When the amount of sucrose increases, the separation into two phases-morphologically and chemically different-is observed. Thermal analysis confirms complicated mechanism of thermal degradation of such composites and shows 
that P123 is present in the final samples after extraction. FT-IR analysis provides a clear evidence for the presence of carbonyl groups, probably due to the thermal decomposition of sucrose and products of its hydrolysis.

Acknowledgements M. Barczak thanks to Polish Ministry of Science and Higher Education for supporting the research under Grant No. NN204 272639. Prof. M. Jaroniec is acknowledged for calculation of KJS pore size distributions.

Open Access This article is distributed under the terms of the Creative Commons Attribution Noncommercial License which permits any noncommercial use, distribution, and reproduction in any medium, provided the original author(s) and source are credited.

\section{References}

1. Yang H, Zhao D. Synthesis of replica mesostructures by the nanocasting strategy. J Mater Chem. 2005;15:1217-31.

2. Wan Y, Zhao D. On the controllable soft-templating approach to mesoporous silicates. Chem Rev. 2007;107:2821-60.

3. Van Der Voort P, Vercaemst C, Schaubroeck D, Verpoort F. Ordered mesoporous materials at the beginning of the third millennium: new strategies to create hybrid and non-siliceous variants. Phys Chem Chem Phys. 2008;10:347-60.

4. Taguchi A, Schüth F. Ordered mesoporous materials in catalysis. Microporous Mesoporous Mater. 2005;77:1-45.

5. Trewyn BG, Giri S, Slowing II, Lin VSY. Mesoporous silica nanoparticle based controlled release, drug delivery, and biosensor system. Chem Commun. 2007;44:3236-44.

6. Hartmann M. Ordered mesoporous materials for bioadsorption and biocatalysis. Chem Mater. 2005;17:4577-93.

7. Zhao DY, Feng J, Huo Q, Melosh N, Fredrickson GH, Chmelka BF, Stucky GD. Triblock copolymer synthesis of mesoporous silica with periodic 50 to 300 Angstrom probes. Science. 1998;279: $548-52$.

8. Zhao DY, Huo Q, Feng J, Chmelka BF, Stucky GD. Nonionic triblock and star diblock copolymer and oligomeric surfactant syntheses of highly ordered, hydrothermally stable, mesoporous silica structures. J Am Chem Soc. 1998;120:6024-36.

9. Goltner CG, Henke S, Weissenberger MC, Antonietti M. Mesoporous silica from lyotropic liquid crystal polymer templated. Angew Chem Int Ed. 1998;37:613-6.

10. Zhang F, Yan Y, Yang H, Meng Y, Yu C, Tu B, Zhao D. Understanding effect of wall structure on the hydrothermal stability of mesostructured silica SBA-15. J Phys Chem B. 2005;109: 32-8273.
11. Jun S, Joo SH, Ryoo R, Kruk M, Jaroniec M, Liu Z, Ohsuna T, Terasaki O. Synthesis of new nanoporous carbon with hexagonally ordered mesostructure. J Am Chem Soc. 2000;122:10712-3.

12. Kruk M, Jaroniec M, Ko CH, Ryoo R. Characterization of the porous structure of SBA-15. Chem Mater. 2000;12:1961-8.

13. Joo SH, Ryoo R, Kruk M, Jaroniec M. Evidence for general nature of pore interconnectivity in 2-dimensional hexagonal mesoporous silicas prepared using block copolymer templated. J Phys Chem B. 2002;106:4640-6.

14. Yiu HHP, Wright P, Botting NP. Enzyme immobilisation using SBA-15 mesoporous molecular sieves with functionalised surfaces. J Mol Catal B. 2001;15:81-92.

15. Chong ASM, Zhao XS. Functionalization of SBA-15 with APTES and characterization of functionalized materials. J Phys Chem B. 2003;107:12650-7.

16. Barczak M, Pikus S, Skrzydło-Radomańska B, Dąbrowski A. Synthesis, structure and adsorption properties of nanoporous SBA-15 materials with framework and surface functionalities. Adsorption. 2009;15:278-86.

17. Wang X, Lin KSK, Chan JCC, Cheng S. Direct synthesis and catalytic. SBA-15 mesoporous materiale. J Phys Chem B. 2005;109: $1763-9$.

18. Kao HM, Liao CH, Palani A, Liao YC. One-pot synthesis of ordered and stable cubic mesoporous silica SBA-1 functionalized with amino functional groups. Microporous Mesoporous Mater. 2008;113:212-23.

19. Barrett EP, Joyner LG, Halenda P. The determination of pore volume and area distributions in porous substances. I. Computations from nitrogen isotherms. J Am Chem Soc. 1951;73:373-80.

20. Jaroniec M, Solovyov LA. Improvement of the Kruk-JaroniecSayari method for pore size analysis of ordered silicas with cylindrical mesopores. Langmuir. 2006;22:6757-60.

21. Brunauer JS, Emmett PH, Teller E. Adsorption of gases in multimolecular layers. J Am Chem Soc. 1938;60:309-19.

22. Barczak M, Dąbrowski A, Iwan M, Rzączyńska Z. Mesoporous organosilicas functionalized by alkyl groups: synthesis, structure and adsorption properties. J Phys Conf Ser. 2009;146:012002.

23. Coutinho AC, Quintella SA, Araujo AS, Barros JMF, Pedrosa AMG, Fernandes VJ, Souza JB. Thermogravimetry applied to characterization of SBA-15 nanostructured material. J Therm Anal Calorim. 2007;87:457-61.

24. Gabelica Z, Charmot A, Vataj R, Soulimane R, Barrault J, Valange $\mathrm{S}$. Thermal degradation of iron chelate complexes adsorbed on mesoporous silica and alumina. J Therm Anal Calorim. 2009; 95:445-54.

25. Barczak M, Dąbrowski A, Pikus S, Ryczkowski J, Borowski P, Kozak M. Studies of the structure and chemistry of SBA-15 organosilicas functionalized with amine, thiol, vinyl and phenyl groups. Adsorption. 2010;16:457-63. 